\title{
The Overlap between Headache and Epilepsy in the Light of Recent Advances in Medical Genetics
}

\author{
Alessandro Ferretti, Maria Chiara Paolino and Pasquale Parisi* \\ Child Neurology, Headache Paediatric Center, Paediatric Sleep Disorders, NESMOS Department, Chair of Pediatrics, Faculty of Medicine and Psychology, Sapienza \\ University, c/o Sant'Andrea Hospital, Rome, Italy
}

Keywords: Migraine; Headache; Epilepsy; Ictal epileptic headache; Classification criteria; Genetic advances; Epidemiology; Comorbidity; Overlap

Although the nature of epilepsy and headache association has not been full understand, during the past 100 years several potential mechanisms have been proposed to explain the link between these two conditions [1]. To get a definitive international consensus on the crossover between headache and epilepsy, many authors have spent endless efforts to reach an agreement on the various aspects of this intriguing concept.

The clinical hypothesis that headache and epilepsy are related derives from 19th century literature data. Sir Gowers first suggested that "migraine is in the borderland of epilepsy", and we can say now, in the light of modern knowledge, that neurotransmitters and ion channel dysfunctions can play a leading role. Both are characterized by transient attacks of altered brain function with a spectrum of common pathophysiological, clinical and therapeutic features. Furthermore, epilepsy and migraine may mimic each other.

More than one hundred years later, in the era of digital EEG recordings, we can firmly report that sometimes "headache itself can even be epilepsy", and, in certain cases (probably not recognized), "the headache can represent the only ictal epileptic phenomenon" $[2,3]$. In this regards, there have been proposed new criteria for the event termed "ictal epileptic headache" (IEH) in which "headache is the sole ictal epileptic manifestation" [4].

According to our recently proposed criteria for IEH, there are serious doubts about the real existence of the phenomenon called "migralepsy" [5,6]. This term, derived from migra(ine) and (epi) lepsy, has been first used by Lennox and Lennox, in 1960 to describe a condition wherein "ophthalmic migraine with perhaps nausea and vomiting was followed by symptoms characteristic of epilepsy".

Recent scientific evidences on the IEH, have convinced us that the "migralepsy" concept is exceptional or, even, it does not exist. In our opinion, the "migraine-epilepsy" sequence, defined as "migralepsy", could simply be a seizure that starts with an "ictal headache", and continues with a seizure (sensory-motor partial or generalized), fitting thus in these cases into codified criteria for "Hemicrania Epileptica" $[7,8]$.

Moreover it is significant to underline that rarely in IEH cases, the headache ictal origin had been demonstrated (by chance in drugresistant epileptic patients, during pre-surgical investigations) only by deep electrode studies. In other words, while epileptiform abnormalities usually sustains a diagnosis of epilepsy, not rarely IEH patients are characterized by the absence of clear epileptic spike-and-wave activity. Missed recognitions of IEH events are due to these reasons $[9,10]$.

Highlighted these aspects, the overlap between headache and epilepsy should be analyzed from multiple points of view: epidemiological, physiological, etiopathological, and classificative.
Migraineurs show an higher frequency of epilepsy (range 1-17\%) than general population $(0.5-1 \%)$, and at the same time migraine prevalence among patients affected by epilepsy is also higher (range $8-15 \%$ ) than that reported in healthy individuals [11-13]. Especially in children this comorbidity is found often [14].

Seizures and migraine attacks share different pathophysiological mechanisms. Both events may be sign of an underlying brain lesion, or have a probably genetic origin. In this respect, it has been shown that in epilepsy occurs hyperexcitation, while in migraine a brief hyperexcitation period (depolarization) is followed by a long hypoexcitation period (spreading depression), followed again by hyperexcitation, as rebound phenomenon. Moreover, it has been shown that a disexcitability (hyper- and hypo-excitation in the same migraineurs at different points in time) underlines both the phenomenon [1].

Cortical Spreading Depression (CSD) is believed to underlie both migraine and epilepsy $[15,16]$, even in patients affected by migraine without aura. CSD is characterized by a slowly propagating wave of sustained strong neuronal depolarization that generates transient intense spike activity as it progresses into the brain tissue, followed by neural suppression which may last for minutes. The phase of depolarization is associated with a regional cerebral blood flow increase, whereas the phase of reduced neural activity is associated with a reduction in blood flow [17].

It is crucial to remark that while an epileptic discharge can birth exclusively in the cortex, the pathophysiology of headache has its origin at multiple cortico-subcortical levels. Thus, the two cascades of events (headache and epilepsy) show independent ways that can crossover only at the cortical level $[18,19]$. In headache and epilepsy overlap, after the cortical cascade of events, their onset and propagation are triggered when CSD and epileptic focus reach a definite threshold, lower for CSD than for seizure $[6,8,20,21]$. Moreover, the onset of CSD and that of the epileptic seizure may facilitate each other [22].

Triggering factors may be environmental or individual (genetically determined or not), determining an ions flow and leading to CSD, through neuronal and glial cytoplasmic bridges rather than through

*Corresponding author: Prof. Pasquale Parisi, Child Neurology, Headache Paediatric Center, Paediatric Sleep Disorders, Chair of Paediatrics, NESMOS Department, Faculty of Medicine \& Psychology, Sapienza University, c/o Sant'Andrea Hospital, Via di Grottarossa, 1035-1039, 00189, Rome, Italy, Fax: 0039-6-33775941; E-mail: pasquale.parisi@uniroma1.it

Received October 03, 2013; Accepted December 09, 2013; Published December 11,2013

Citation: Ferretti A, Paolino MC, Parisi P (2013) The Overlap between Headache and Epilepsy in the Light of Recent Advances in Medical Genetics. J Mol Genet Med 7: 82. doi:10.4172/1747-0862.1000082

Copyright: (C) 2013 Ferretti A, et al. This is an open-access article distributed under the terms of the Creative Commons Attribution License, which permits unrestricted use, distribution, and reproduction in any medium, provided the original author and source are credited 
Citation: Ferretti A, Paolino MC, Parisi P (2013) The Overlap between Headache and Epilepsy in the Light of Recent Advances in Medical Genetics. J Mol Genet Med 7: 82. doi:10.4172/1747-0862.1000082

Page 2 of 3

interstitial spaces, as usually occurs in the spreading of epileptic seizures.

Strong support for a shared genetic basis between headache and epilepsy comes from clinical/EEG and genetic studies on familial hemiplegic migraine, a rare monogenic subtype of migraine [23-25], where errors in the same gene may be associated with migraine in some cases and with epilepsy in others [26].

Gene mutations have been found using positional cloning techniques, mutation analysis, and traditional linkage analysis which require testing several hundreds or thousands of genetic markers across the genome and selecting those chromosomal regions that most closely segregate with the disease. A second linkage analysis strategy is affected sib-pair analysis in which affected siblings shared chromosomal regions that occur with a probability higher than by chance alone are identified. Candidate genes in the shared regions are then characterized testing single-nucleotide polymorphism (SNPs). The objective is to identify SNPs, and thus gene alleles, whose frequency significantly differs between cases and controls and increases susceptibility to the disease. A third, hypothesis-driven approach is direct testing of candidate genes in case-control association studies [27].

Recent studies propose common genetic substrates and a correlation between phenotypic and genotypic linked to mutations in some ion transporters genes, including CACNA1A, ATP1A2, and SCN1A [2832]. Other genetic findings are reported in literature to explain the link between migraine and epilepsy. They include mutations on SLC1A3, a member of the solute carrier family that encodes excitatory amino acid transporter 1, 57 POLG58, C10 and F259, which encode mitochondrial DNA polymerase and helicase twinkle [33]. Recently numerous genome-wide association studies and meta-analysis are identifying loci associated migraine and epilepsy susceptibility [34].

The fundamentals of molecular genetics are important for clinicians to understand unprecedented insights into the pathogenesis of these disorders, and reveal promising treatment targets for future drug development. Further genetic, experimental and clinical investigations (molecular and multicenter clinical trials) are necessary to better understand this complex relationship; this approach could be the basis to create a definitive international consensus on this matter.

\section{Conflict of Interest}

We have no conflict of interests to disclose regarding this "Invited Editorial".

\section{References}

1. Parisi $P$, Striano $P$, Negro A, Martelletti $P$, Belcastro V (2012) Ictal epileptic headache: an old story with courses and appeals. J Headache Pain 13: 607613

2. Parisi $P$, Striano $P$, Belcastro V (2013) The crossover between headache and epilepsy. Expert Rev Neurother 13: 231-233.

3. Parisi P, Striano P, Verrotti A, Villa MP, Belcastro V (2013) What have we learned about ictal epileptic headache? A review of well-documented cases. Seizure 22: 253-258.

4. Parisi P, Striano P, Trenité DG, Verrotti A, Martelletti P, et al. (2012) 'Ictal epileptic headache': recent concepts for new classifications criteria. Cephalalgia 32: $723-724$

5. Kasteleijn-Nolst Trenité D, Parisi P (2012) Migraine in the borderland of epilepsy: "migralepsy" an overlapping syndrome of children and adults? Epilepsia 53 Suppl 7: 20-25.

6. Verrotti A, Striano P, Belcastro V, Matricardi S, Villa MP, et al. (2011) Migralepsy and related conditions: advances in pathophysiology and classification. Seizure 20: $271-275$
7. Parisi P, Kasteleijn-Nolst Trenité DG (2010) "Migralepsy": a call for revision of the definition. Epilepsia 51: 932-933.

8. Belcastro V, Striano P, Kasteleijn-Nolst Trenité DG, Villa MP, Parisi P (2011) Migralepsy, hemicrania epileptica, post-ictal headache and "ictal epileptic headache": a proposal for terminology and classification revision. J Headache Pain 12: 289-294.

9. Striano P, Belcastro V, Parisi P (2012) From "migralepsy" to "ictal epileptic headache" concept. Epilepsy Behav 23: 392

10. Belcastro V, Striano P, Parisi P (2013) Interictal and periictal headache in patients with epilepsy: migraine-triggered seizures or epilepsy-triggered headache? Eur J Neurol 20: 1333-1334.

11. Leniger T, Isbruch K, von den Driesch S, Diener HC, Hufnagel A (2001) Seizure-associated headache in epilepsy. Epilepsia 42: 1176-1179.

12. Toldo I, Perissinotto E, Menegazzo F, Boniver C, Sartori S, et al. (2010) Comorbidity between headache and epilepsy in a pediatric headache center. $J$ Headache Pain 11: 235-240.

13. Verrotti A, Coppola G, Spalice A, Di Fonzo A, Bruschi R, et al. (2011) Peri-ictal and inter-ictal headache in children and adolescents with idiopathic epilepsy: a multicenter cross-sectional study. Childs Nerv Syst 27: 1419-1423.

14. Clarke T, Baskurt Z, Strug LJ, Pal DK (2009) Evidence of shared genetic risk factors for migraine and rolandic epilepsy. Epilepsia 50: 2428-2433.

15. Moskowitz MA, Nozaki K, Kraig RP (1993) Neocortical spreading depression provokes the expression of c-fos protein-like immunoreactivity within trigeminal nucleus caudalis via trigeminovascular mechanisms. J Neurosci 13: 1167 1177 .

16. Zhang X, Levy D, Kainz V, Noseda R, Jakubowski M, et al. (2011) Activation of central trigeminovascular neurons by cortical spreading depression. Ann Neurol 69: 855-865.

17. Woods RP, lacoboni M, Mazziotta JC (1994) Brief report: bilateral spreading cerebral hypoperfusion during spontaneous migraine headache. $\mathrm{N}$ Engl J Med 331: 1689-1692.

18. Parisi P, Piccioli M, Villa MP, Buttinelli C, Kasteleijn-Nolst Trenité DG (2008) Hypothesis on neurophysiopathological mechanisms linking epilepsy and headache. Med Hypotheses 70: 1150-1154

19. Parisi $P$ (2009) Why is migraine rarely, and not usually, the sole ictal epileptic manifestation? Seizure 18: 309-312.

20. Parisi P (2009) Who's still afraid of the link between headache and epilepsy? Some reactions to and reflections on the article by Marte Helene Bjørk and coworkers. J Headache Pain 10: 327-329.

21. Kasteleijn-Nolst Trenite DG, Verrotti A, Di Fonzo A, Cantonetti L, Bruschi R, et al. (2010) Headache, epilepsy and photosensitivity: how are they connected? Headache Pain 11: 469-476.

22. Cai S, Hamiwka LD, Wirrell EC (2008) Peri-ictal headache in children: prevalence and character. Pediatr Neurol 39: 91-96.

23. Escayg A, Goldin AL (2010) Sodium channel SCN1A and epilepsy: mutations and mechanisms. Epilepsia 51: 1650-1658.

24. Riant F, Ducros A, Ploton C, Barbance C, Depienne C, et al. (2010) De novo mutations in ATP1A2 and CACNA1A are frequent in early-onset sporadic hemiplegic migraine. Neurology 75: 967-972.

25. De Fusco M, Marconi R, Silvestri L, Atorino L, Rampoldi L, et al. (2003) Haploinsufficiency of ATP1A2 encoding the $\mathrm{Na}+/ \mathrm{K}+$ pump alpha2 subunit associated with familial hemiplegic migraine type 2. Nat Genet 33: 192-196.

26. Vanmolkot KR, Kors EE, Hottenga JJ, Terwindt GM, Haan J, et al. (2003) Nove mutations in the $\mathrm{Na}+, \mathrm{K}+-$ ATPase pump gene ATP1A2 associated with familial hemiplegic migraine and benign familial infantile convulsions. Ann Neurol 54 360-366.

27. Silberstein S, Dodick D (2013) Migraine genetics - a review: part I. Headache 53: $1207-1217$

28. Rogawski MA (2012) Migraine and Epilepsy_Shared Mechanisms within the Family of Episodic Disorders. 4th edition. Bethesda (MD): National Center for Biotechnology Information (US).

29. Zangaladze A, Asadi-Pooya AA, Ashkenazi A, Sperling MR (2010) Sporadic hemiplegic migraine and epilepsy associated with CACNA1A gene mutation. Epilepsy Behav 17: 293-295 
Citation: Ferretti A, Paolino MC, Parisi P (2013) The Overlap between Headache and Epilepsy in the Light of Recent Advances in Medical Genetics. J Mol Genet Med 7: 82. doi:10.4172/1747-0862.1000082

Page 3 of 3

30. Costa C, Prontera P, Sarchielli P, Tonelli A, Bassi MT, et al (2013) A novel ATP1A2 gene mutation in familial hemiplegic migraine and epilepsy. Cephalalgia

31. Cestèle S, Labate A, Rusconi R, Tarantino P, Mumoli L, et al. (2013) Divergent effects of the T1174S SCN1A mutation associated with seizures and hemiplegic migraine. Epilepsia 54: 927-935

32. Frosk P, Mhanni AA, Rafay MF (2013) SCN1A mutation associated with intractable myoclonic epilepsy and migraine headache. J Child Neurol 28: 389391.
33. Bianchin MM, Londero RG, Lima JE, Bigal ME (2010) Migraine and epilepsy: a focus on overlapping clinical, pathophysiological, molecular, and therapeutic aspects. Curr Pain Headache Rep 14: 276-283.

34. Anttila V, Winsvold BS, Gormley P, Kurth T, Bettella F, et al. (2013) North American Brain Expression Consortium; UK Brain Expression Consortium International Headache Genetics Consortium Genome-wide meta-analysis identifies new susceptibility loci for migraine. Nat Genet 45: 912-917. 